\title{
Relation between the onset and end of the South American summer monsoon and rainfall in subtropical South America
}

\author{
Marcela González ${ }^{1, *}$, Vicente Barros ${ }^{1,2}{ }^{2}$ Moira Doyle ${ }^{1}$ \\ ${ }^{1}$ Department of Atmospheric Sciences, University of Buenos Aires 2 piso, Pabellón II, Ciudad Universitaria, \\ 1428 Capital Federal, Buenos Aires, Argentina \\ ${ }^{2}$ Consejo de Investigaciones Científicas y Técnicas (CONICET), Buenos Aires, Argentina
}

\begin{abstract}
This paper explores the relation between the inter-annual variability of the austral South American monsoon onset and end dates and the inter-annual variability of rainfall in September and May in subtropical South America. Outgoing longwave radiation (OLR) was used to define the onset and end dates of the convective season. Precipitation records were taken from national or state agencies of the region. Other surface and tropospheric variables were taken from NCEP/NCAR reanalysis. A 5 d canonical correlation analysis between rainfall in subtropical South America east of the Andes and the tropical convection of the South American monsoon estimated by the OLR shows that these variables are related during the austral autumn and spring. In both seasons, the first modes are very similar and indicate that rainfall in southern Brazil is negatively correlated with convection over the eastern part of the tropical continent. Because a delay (an early advent) of the monsoon end increases (reduces) the period with convection over the tropics, while the contrary occurs with the onset, rainfall composites between months corresponding to cases with extreme dates at the onset or the end of the tropical convective season show an important rainfall signal in southern Brazil during May and September. During May the early (delayed) end date is associated with enhanced (decreased) rainfall in most of the subtropical region. In September, the early (delayed) onset is associated with decreased (enhanced) rainfall only in southern Brazil, while in Argentina and Uruguay there is an opposite signal, non symmetric with respect to the May case. In May, the mean low-level flow of moisture from the tropical continent over eastern subtropical South America is considerably greater in the cases with an advanced monsoon end than in those with a delayed end, while in September, the composite differences between years with an early and a delayed onset show enhanced moisture advection from the tropical continent over most of Argentina and Uruguay, and a reduction over southern Brazil and Paraguay.
\end{abstract}

KEY WORDS: Subtropical South America $\cdot$ Rainfall · Monsoon - Tropical convection · Outgoing longwave radiation

Resale or republication not permitted without written consent of the publisher

\section{INTRODUCTION}

Subtropical South America is known to be one of the regions of the world with an important El Niño-Southern Oscillation (ENSO) signal in the precipitation field (Ropelewski \& Halpert 1996, Kiladis \& Diaz 1989). This

*E-mail: gonzalez@at.fcen.uba.ar signal varies along each of the ENSO phases, and it differs between sub-regions (Grimm et al. 2000). For instance, the inter-annual correlation between ENSO indicators and subtropical rainfall is strong during spring, but there is almost no correlation in summer, when the monsoon season has been established (Rao \& Hada 1990, Grimm et al. 1998). An exception to the latter feature is a tendency toward dry conditions in the Bolivian Plateau during the austral summer of the 
warm phase of ENSO (Aceituno \& Garreaud 1995). In addition, sea-surface temperature (SST) anomalies in the neighboring Atlantic have been documented as another forcing for the inter-annual variability of the regional precipitation (Diaz et al. 1998, Doyle \& Barros 2000). However, even during the months with stronger signals, the ENSO and the Atlantic SST forcing account for only a small fraction of the inter-annual rainfall variance. Thus, other regional or remote sources for this variability cannot be disregarded.

Because of the barrier formed by the Andes Mountains, the water vapor entering at low levels in subtropical South America comes either from the tropical continent or from the Atlantic Ocean. In the first case, due to the presence of the Andes Mountains, the easterly low-level flow at low latitudes is channeled towards the south between the Bolivian Plateau and the Brazilian Planalto, advecting warm and humid air to southern Brazil, Paraguay, Uruguay and subtropical Argentina (Lenters \& Cook 1995, Wang \& Paegle 1996, Zhou \& Lau 1997, Kousky 1999). Often, in this flow there is an intense low-level jet that enhances humid and warm air advection (Douglas et al. 1998, Paegle 2000 , Silva Dias 2000). At about $20^{\circ} \mathrm{S}$, this flow shifts its direction 2 or 3 times a month, going either eastward to the South Atlantic Convergence Zone (SACZ) or southward to subtropical Brazil and Argentina (Nogués-Paegle \& Mo 1997).

Although, by contrast with what occurs in typical monsoon regions, a seasonal reversal of wind direction at low levels is not observed at a continental scale, rainfall over tropical South America has the characteristic annual cycle of a monsoon regime (Zhou \& Lau 1998). Large-scale convection enters into the Southern Hemisphere in austral spring and moves towards the southeast, rapidly reaching central Brazil (Kousky 1988, Marengo et al. 2001). The rainy season begins in September not only in the tropical region but also in the subtropical area of Bolivia, Paraguay and western Argentina, and it lasts until the middle of the austral autumn (Prohaska 1976), when the convection moves northward towards the Northern Hemisphere. During this part of the year, the low-level flow from the tropics carries considerably more water vapor toward the western subtropical region than it does during the rest of the year (Doyle \& Barros 2000, Labraga et al. 2000). Associated with this annual cycle in the moisture advection from the north, there is a dry season during winter in most of western subtropical Argentina (González \& Barros 1996).

Kousky (1988) used outgoing longwave radiation (OLR) data to determine the date of the climatological onset and end of the convective monsoon. Sugahara (1991) studied the onset of the rainy season in different areas of the Amazon, and detected a large spatial vari- ability of this event. The same conclusion was reached by Marengo et al. (2001), who observed that the onset occurs first in the western Amazon. There are indications that the wet season is started by synoptic events and then evolves controlled by large-scale conditions (Fu et al. 1999). In addition, SSTs in the Caribbean Sea and in the equatorial Pacific modulate the inter-annual variability of both the onset and the end of the convective season over South America (González \& Barros 2000).

No matter which factors influence the onset and end monsoon dates, these dates have a year-to-year variability that is probably related to the inter-annual variability of rainfall in subtropical South America during the months of September and May, as has already been documented for the onset case (González \& Barros 1998, hereinafter referred to as GB98). Therefore, the aim of this paper is to explore how the inter-annual variability of the southern monsoon end date relates to the inter-annual variability of rainfall in the austral autumn in subtropical South America, expanding also the discussion of the onset made by GB98.

\section{DATA}

At low latitudes, OLR is indicative of the cloud altitude and, therefore, of the intensity of convection. In addition, OLR data are useful for providing an estimate of large-scale precipitation in the tropics (Arkin \& Ardanuy 1989, Morrissey \& Graham 1996). Thus, OLR data have been used as a proxy for rainfall in tropical convective regimes in studies of inter-annual variability (Heddinhaus \& Krueger 1981, Liebmann \& Hartmann 1982, Hastenrath 1984, Aceituno 1988) and of the annual cycle (Horel et al. 1989, Mitchell \& Wallace 1992). In this work, OLR measurements obtained from polar NOAA operational satellites, averaged on a $2.5^{\circ}$ latitude-longitude array taken from the Climate Diagnostic Center (CDC) of the National and Oceanographic Administration (NOAA), were used to study convection over tropical South America. There are some biases in OLR data for the period 1974-1977 as compared to those after 1979. They arise from the use of different sensors and different equator-crossing times (Gruber \& Krueger 1984). These biases are not important when the day and night observations are averaged, thus allowing the study of the inter-annual variability (Janowiak et al. 1985). Consequently, in order to employ the longest possible record, the complete available data (1975-1997) were used, but the day and night observations of the OLR were averaged. This filters the diurnal cycle (Schmetz \& Liu 1988) and reduces the differences between data of different satellites resulting from various equator-crossing times (Kousky 1988). The daily value was considered miss- 
ing when either the day or the night data were not available. The missing values were recovered by spatial interpolation, except for 1978, when data were not available for most of the year. In the case of the OLR composites presented in Section 5, they were directly constructed from monthly averages available from the CDC.

Rainfall series were taken from more than 100 stations located between 22 and $40^{\circ} \mathrm{S}$ in subtropical South America, east of the Andes. The Argentine National Meteorological Service and the National Direction of Meteorology of Paraguay provided the records for Argentina and Paraguay, respectively. Most of the series for Brazil were obtained from the Institute of Agricultural Research of Rio Grande do Sul and from the National Agency of Electricity. Data from Uruguay were taken from the Monthly Climatic Data for the World files of the National Center for Atmospheric Research (NCAR). In this set of 107 monthly records, there is less than $2 \%$ missing data, and none of the series has more than $10 \%$ of the data absent. Precipitation series were averaged on a $3^{\circ}$ latitude by $3^{\circ}$ longitude array to smooth singularities proper to single rain-gauge measurements. Since most rainfall data subsequent to 1997 are not yet available from the observing agencies, and OLR is only available since 1975, the study was restricted to the period 1975-1997.

Low-level moisture flow, the product of specific humidity and the wind vectors $(q \cdot V)$, was calculated using the NCEP/NCAR daily reanalysis (Kalnay et al. 1996). This product was calculated daily at each level, integrated vertically from the surface to $700 \mathrm{hPa}$ and then averaged for every month. Mo \& Higgins (1996) compared the moisture transport derived from NCEP/NCAR and the NASA Data Assimilation Office reanalysis. They found a general agreement with some regional differences. In South America, there is high uncertainty. In the case of the low-level jet, Doyle (2001) compared the integrated specific humidity below $700 \mathrm{hPa}$ with data from the NASA Water Vapor Project (Randel et al. 1996) for the period 1988-1992. Comparison of monthly averages in austral South America shows similar patterns with a spatial correlation between both sets higher than 0.8 in $98 \%$ of the months and a mean of 0.87 .

Monthly values of the omega vertical velocities at various levels and $200 \mathrm{hPa}$ wind vectors were also taken from the NCEP/NCAR reanalysis (Kalnay et al. 1996). The problem with these reanalyses, arising from the assimilation of the Australian sea-level pressure estimates erroneously shifted $180^{\circ}$ in longitude in the southern oceans for the 1976-1992 period, had a minor overall effect on monthly and longer-term time scales, as indicated in the assessment by NCEP/NCAR (see http://wesley.wwb.noaa.gov/paobs/).

\section{TROPICAL OLR AND SUBTROPICAL RAINFALL RELATIONSHIP IN SOUTH AMERICA DURING THE TRANSITION SEASONS}

Both the convection over tropical South America and the rainfall in the subtropical western plains of Paraguay and Argentina begin in September, finishing the dry season that extends during the austral winter (Prohaska 1976). The rainy season in these regions lasts until the austral autumn, when the main convective activity moves toward the Northern Hemisphere. GB98 have made independent principal component analyses (PCAs) of the mean annual cycle of both the tropical OLR and precipitation in subtropical Argentina. In each case, the first principal component (PC) represents the mean annual field, and it has small variability in its eigenvector throughout the year. The first PC in the case of the OLR showed minimum (maximum) convection at equatorial latitudes in the western part of the continent but only to the east of the Andes Mountains, while in the case of subtropical rainfall, the first PC was dominated by a zonal gradient with increasing precipitation towards the east. The second eigenvectors in both cases had a quasi-first harmonic behavior. The second OLR PC presented a dipole structure with opposite centers in central America and central Brazil, and the second subtropical rainfall PC had the maximum variability in northwestern Argentina. The second eigenvectors were highly correlated (0.93), indicating in a quantitative way the almost coincident seasonal variability of both fields. This simultaneous timing can be attributed to the common influence from the annual cycle of the solar heating (Prohaska 1976) or else to an additional physical and direct link between the precipitation processes of these regions.

In order to explore the second alternative, a canonical correlation analysis (CCA; Green 1978) between pentad (5 d sums) of subtropical rainfall and tropical OLR during autumn and spring was performed. The tropical area for OLR anomalies was taken over the South American continent between $2.5-22.5^{\circ} \mathrm{S}$ and $37.5-77.5^{\circ} \mathrm{W}$. This region includes most of the summer convection, and it has the maximum variability on the annual OLR field (GB98). The precipitation field was analyzed over the continent east of the Andes, between 22.5 and $38^{\circ} \mathrm{S}$.

The CCA was performed over standardized variables. Consequently, since their mean fields were subtracted, it is convenient to show them to facilitate the understanding of the CCA results (Fig. 1). The subtropical rainfall fields are similar in both seasons. They have a maximum over southern Brazil, $100 \mathrm{~mm}$ higher in spring than in autumn. Seasonal rainfall decreases towards the west with an almost zonal gradient. In the OLR field, the maximum in both seasons is in the 

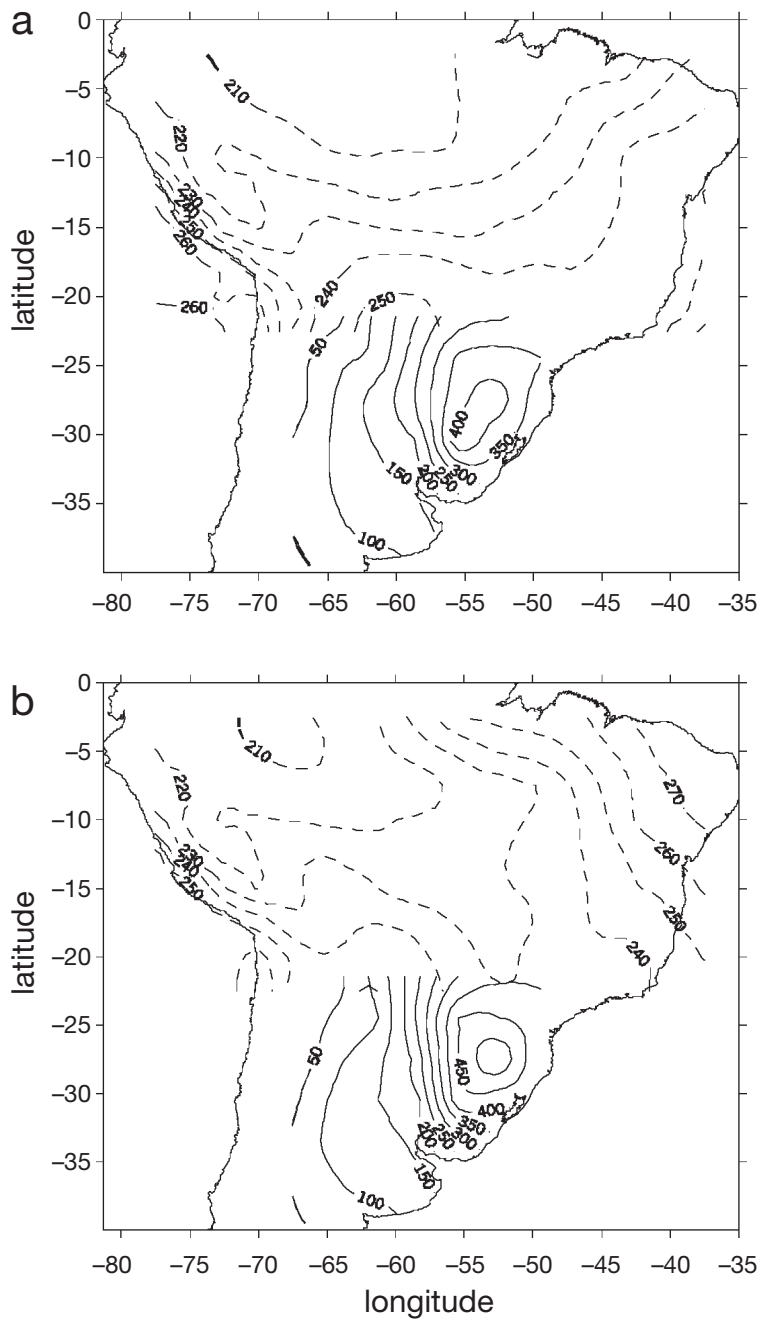

Fig. 1. Mean outgoing longwave radiation (OLR, $\mathrm{W} \mathrm{m} \mathrm{m}^{-2}$; upper contours) and rainfall ( $\mathrm{mm}_{\text {; }}$ lower contours) fields (a) in autumn and (b) in spring for the 1975-1997 period

northwest of the analyzed region. The main differences are in the northeast, where high OLR values in spring are indicative that the lack of convection persists during this season.

In order to reduce the number of variables involved, a PCA was applied to both pentad rainfall and OLR data. Only the components that were considered significant using the diagram of Lev's technique (Green 1978) were retained for the reconstructed fields used in the CCA. In each case, these components jointly explain more than $90 \%$ of the variance in each variable. Table 1 shows the CC coefficient for the first 3 modes.

The first canonical modes are remarkably similar in both seasons, associating greater (lower) convection in the eastern part of the tropical region with lower (greater) than normal rainfall and convection over most of subtropical South America (Fig. 2). This dipole
Table 1. Canonical correlation summary

\begin{tabular}{|lc|}
\hline Canonical pair & Canonical correlation \\
\hline 1 (autumn) & 0.67 \\
2 (autumn) & 0.54 \\
3 (autumn) & 0.47 \\
1 (spring) & 0.66 \\
2 (spring) & 0.54 \\
3 (spring) & 0.42 \\
\hline
\end{tabular}

pattern resembles the alternating pattern of the SACZ found by Nogués-Paegle \& Mo (1997) for the intraseasonal variability of the OLR field in the austral summer, in which each phase lasts about $10 \mathrm{~d}$. They found that events with strong (weak) convective activity over the SACZ were associated with negative (positive) rainfall anomalies in the subtropical region to the south of the SACZ. The main difference between the spring and autumn first modes with respect the summer seesaw pattern is that in this pattern the main center of variability is the northern center at the SACZ. On the other hand, in the first modes of the transition season, the main center is the southern one, roughly at the location of the rainfall climatological maximum. Regarding their temporal structure, Fig. 2c and d show the canonical vectors for autumn and spring for 1 year as an example. In autumn, the frequencies of 15 to $20 \mathrm{~d}$ are predominant, which is similar to what is observed in summer with the SACZ variability.

In summer, a strong SACZ is likely associated with enhanced subsidence south of the SACZ, as was found in numerical experiments (Gandú \& Silva Díaz 1998). Thus, the compensatory subsidence mechanism could possibly be associated with the first canonical mode during the transition seasons. However, results in Section 5 indicate that the low-level advection of moisture variability may also play a role.

Areas with local significance at the 0.1 level are large, both in the spring and in the autumn (Fig. 2a,b). To consider the probability that this happens by chance, the percentage of these areas should be compared with results of a binomial distribution, since in terms of probability theory a collection of $N$ independent significant tests is analogous to $N$ samples from a 2-class population, each with given probabilities (Livezey \& Chen 1983). OLR pentad data were averaged on a $2.5^{\circ}$ latitude-longitude array. Hence, due to the scale of the cloud systems, the series of this array are unlikely statistically independent. Therefore, the number of equivalent independent series to be taken as the degrees of freedom in the binomial distribution test is lower than the total number of series. As explained previously, the PCA performed in each fieldOLR and precipitation-retained only the significant components before reconstructing each field to calcu- 

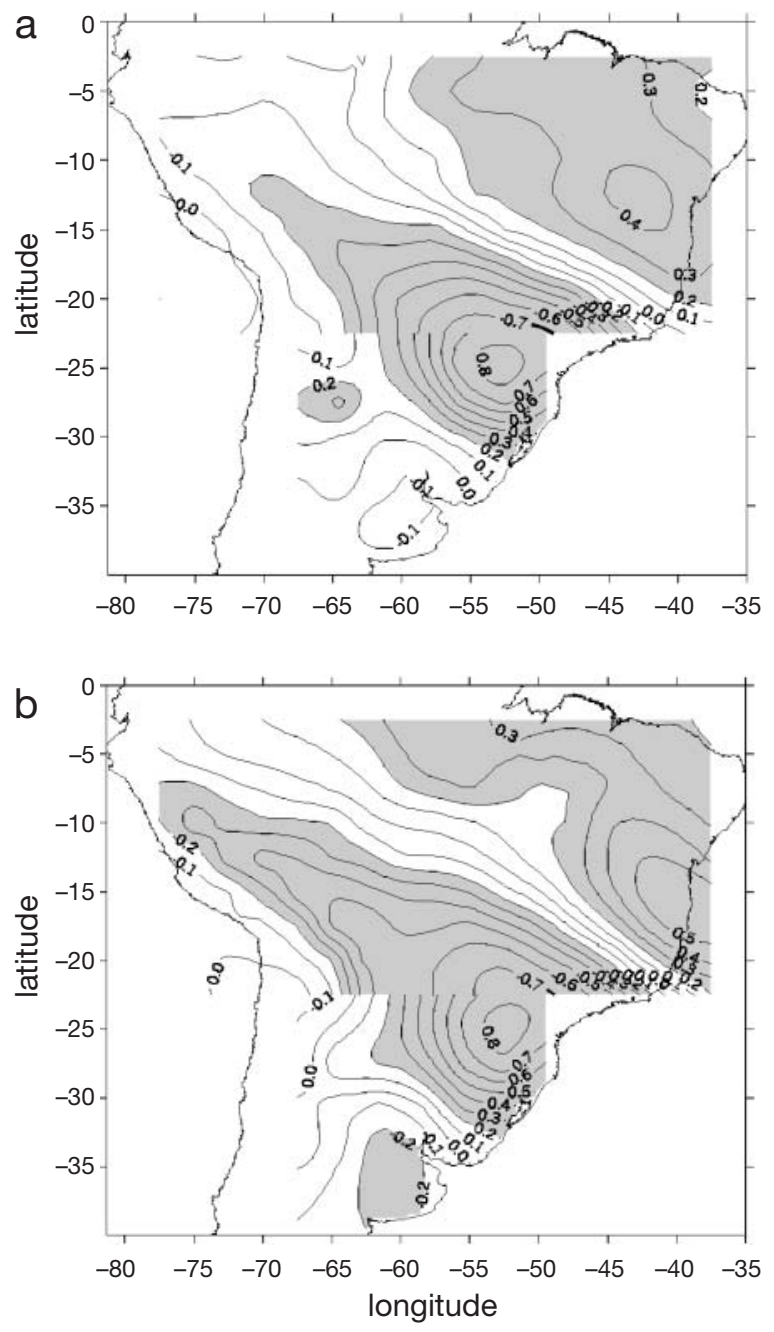

late the CC. Nevertheless, they retained more than $90 \%$ of the variance. Since the respective eigenvectors were orthogonal, the significant PCs can be considered statistically independent, and their number can be used as the degrees of freedom in the binomial test. In the case of the OLR field, the significant PCs were conservatively estimated to be only 10, in both autumn and spring. Then, in order to reject the hypothesis that the significant fields of Fig. 2 are caused by accident with a $10 \%$ probability of being wrong according to the binomial distribution, the number of significant cases should be greater than 3 . That is, more than $30 \%$ of the cases. This is indeed so, since the areas with local significance at the 0.1 level in the OLR component cover more than $80 \%$ in spring and $75 \%$ in autumn. In the case of rainfall, data were averaged on a $3^{\circ}$ latitude array, and again each series cannot be considered statistically independent of the rest. In this case, the number of degrees of freedom can be estimated conservatively according to the significant PCs, which amounted only to 8 , both in the autumn and in
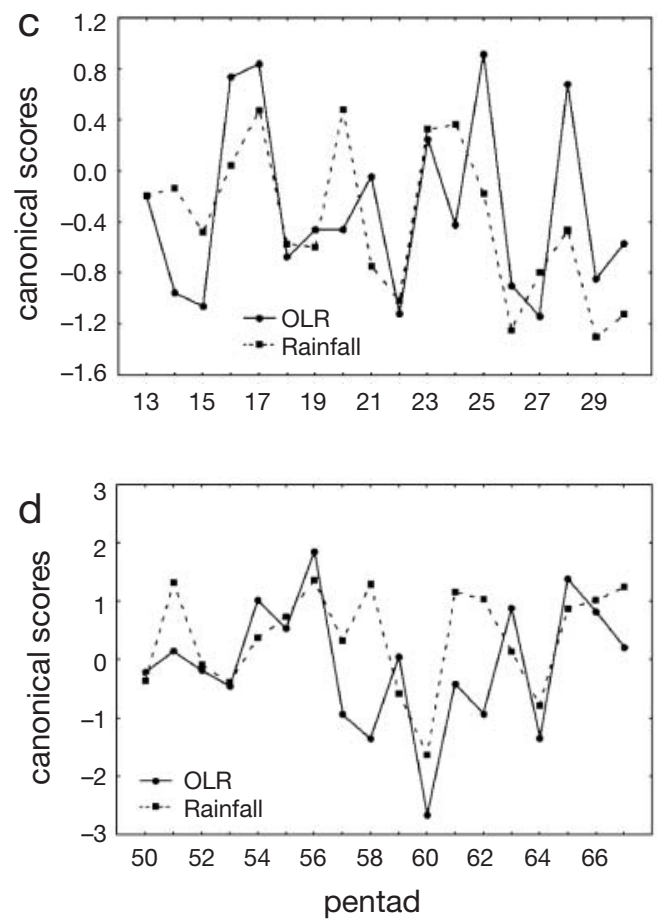

Fig. 2. $(\mathrm{a}, \mathrm{b})$ First mode of canonical correlation between OLR and rainfall for (a) autumn and (b) spring. Significant values at the $90 \%$ level are shaded. $(\mathrm{c}, \mathrm{d})$ Example of canonical score in (c) autumn and (d) spring during 1975

the spring. Then, the rejection of the hypothesis with the same level of probability of being wrong as in the former case implies that the number of significant cases should be again greater than 3. However, now this number is more than $37.5 \%$ of the cases, a percentage that is roughly what is observed in Fig. 2.

There is a remarkable continuity between the OLR and the rainfall correlation fields with the first canonical mode along the selected border between these fields, namely the $22.5^{\circ} \mathrm{S}$ latitude (Fig. 2a,b). This feature is also shared by the second and third canonical modes (not shown). Both variables are, of course, standardized. The continuity of the correlation fields indicates that the intra-seasonal variability of pentad OLR is a good proxy variable for the intra-seasonal variability of pentad rainfall when they are averaged over a lattice of about 2 to $3^{\circ}$. This can also be considered as a further indicator that both variables share large-scale patterns of intra-seasonal variability.

The first canonical modes have greater variability over the east of the continent. Also, in general terms, in 
the second and third modes (not shown) there is more variability in the east than in the west of the continent. This indicates that during the transition seasons the intra-seasonal variability is greater in the east of the South American continent, with a dipole structure along the southwest-northeast direction. On the other hand, the variability of the OLR during the year has its predominant opposed centers in central Brazil and central America (GB98), forming an orthogonal axis with that of the intra-seasonal variability.

Tropical convection and subtropical rainfall share almost simultaneous timing in their annual cycle (GB98). In addition, during the transition seasons both fields have related patterns of intra-seasonal variability, as shown in this section. Hence, the inter-annual variability of the onset and demise dates of the convective season (both features that condition the mean tropical convection in September and May), is very likely related to the inter-annual rainfall variability of these months in subtropical South America. The following section will explore this issue.

\section{SOUTH AMERICAN MONSOON ONSET AND END DATES AND RAINFALL IN SUBTROPICAL SOUTH AMERICA}

The onset and end dates of the convective season were calculated for each box point in the $2.5^{\circ}$ latitudelongitude array with the criterion used by Kousky (1988). He defined the onset date as the first pentad when OLR falls below $240 \mathrm{~W} \mathrm{~m}^{-2}$ and when OLR in 10 out of the 12 preceding (and subsequent) pentads was above (below) $240 \mathrm{~W} \mathrm{~m}^{-2}$. Similarly, he defined the end date as the first pentad when OLR was greater than $240 \mathrm{~W} \mathrm{~m}^{-2}$ and when the OLR in 10 out of the 12 preceding (and subsequent) pentads was below (above) $240 \mathrm{~W} \mathrm{~m}^{-2}$. The value of $240 \mathrm{~W} \mathrm{~m}^{-2}$ was used by many authors as a threshold for deep convection. Involving the preceding and subsequent pentads prevents the definition of these dates by a single event, while at the same time it is possible to capture the inter-annual variability of the OLR trend. Of course, the onset and end dates will depend critically on the threshold used in their definition. However, in the South American tropical regions corresponding to the Southern Hemisphere, the annual cycle of OLR shows a rapid change approximately linear with time during the transition seasons (Marengo et al. 2001). This linearity suggests that, while the onset and end dates critically depend on the threshold chosen, this would not necessarily be the case for their correlations with subtropical rainfall.

Since the convective season progresses southeastward from early September onward, and starts to withdraw to the north in April (Kousky 1988, Marengo et al.
2001), its onset and demise differ from one region to another. However, the intention here is to treat the onset and the end of convection as an overall largescale feature of the South American Summer Monsoon (SASM). Consequently, onset and end dates were averaged in the area between $0-15^{\circ} \mathrm{S}$ and $45-75^{\circ} \mathrm{W}$, excluding the extreme northwest, west of $60^{\circ} \mathrm{W}$ and north of $5^{\circ} \mathrm{S}$, where in some years it was not possible to meet the requirements for the onset or the end date because OLR values remain below $240 \mathrm{~W} \mathrm{~m}^{-2}$ during most of the year. The averages referred to previously were used consistently in the calculation of onset and end dates. The aforementioned area has the maximum convection during the SASM and has the greater OLR annual variability in South America south of the equator (GB98). With these definitions, the mean onset date in this area for the period 1975-1997 was in pentad 54 of the year, i.e. on September 23, with a standard deviation of $11 \mathrm{~d}$, and the mean end date was in pentad 27.5 , i.e. on May 14, with a standard deviation of $9 \mathrm{~d}$.

Inter-annual correlations between the end date and the rainfall accumulated in May are negative all over the region, except in the northwest of Argentina (Fig. 3a). This means that when the end takes place ear-
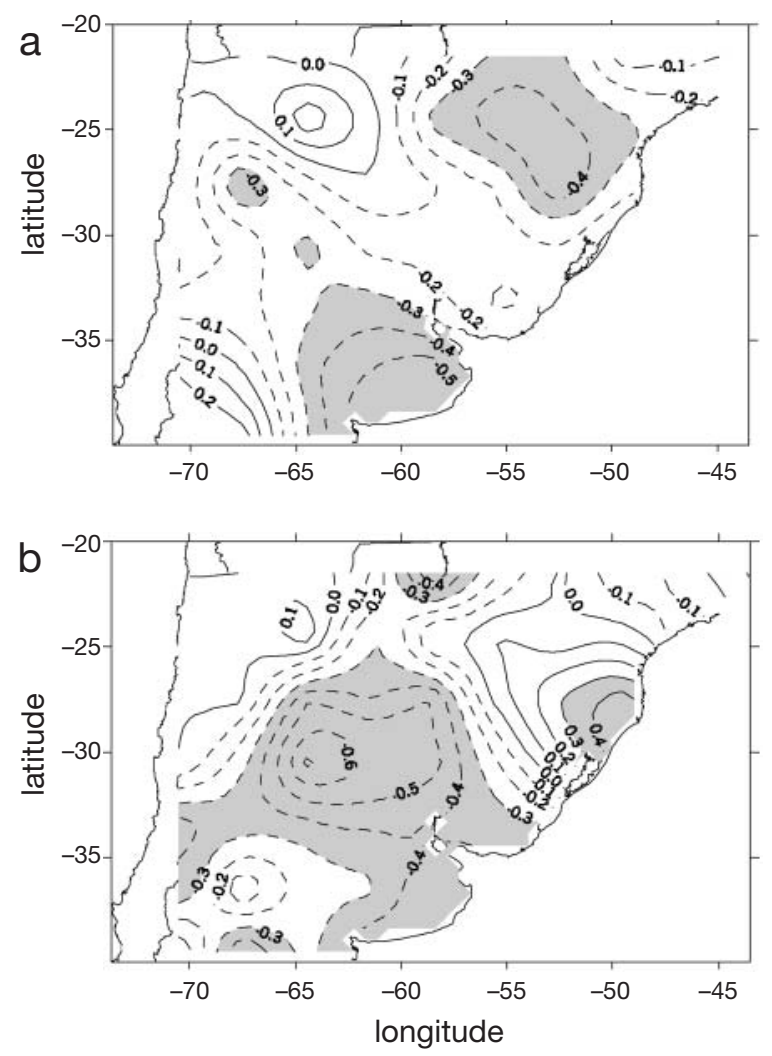

Fig. 3. Interannual correlation (a) between the end date, as defined in the text, and May rainfall and (b) between onset date and September rainfall. Significant values at the $90 \%$ level are shaded 
lier (later) than normal rainfall tends to be greater (less) than normal, especially at the 2 centers with negative significant correlation in southern Brazil and in Buenos Aires Province. However, the area with significant correlation is only a small fraction of the analyzed surface, which together with the few spatially independent data implies that it is not possible to reject the hypothesis that these significant correlations occur by chance. Nevertheless, at least in southern Brazil, the negative correlation nucleus is consistent with the first mode of variability at intra-seasonal scale (Fig. 2b), since the early (delayed) withdrawal of the convective season implies an early (delayed) reduction of convection over the northeast and the central region of Brazil, and consequently, according to the first mode, an enhancement (reduction) of rainfall in southern Brazil.

Since the end date depends on the region, its relationship with subtropical rainfall in South America could be different. Hence, correlations were calculated between May rainfall in subtropical South America and the end dates averaged over each of the regions defined as follows: $0-7.5^{\circ} \mathrm{S}$ and $75-60^{\circ} \mathrm{W}(\mathrm{NW}) ; 0-7.5^{\circ} \mathrm{S}$ and $60-45^{\circ} \mathrm{W}(\mathrm{NE}) ; 7.5-15^{\circ} \mathrm{S}$ and $75-60^{\circ} \mathrm{W}$ (SW); $7.5-15^{\circ} \mathrm{S}$ and $60-45^{\circ} \mathrm{W}$ (SE). Features similar to those in Fig. 3a were observed in the NW, NE and SE cases (not shown). In contrast, no significant response was detected for the SW region, probably because the end date is generally later than May, following the initial SSE-NNW displacement of the end date in the austral autumn.

GB98 described the shift of tropical convection in late southern winter and spring. They found significant inter-annual correlation between September rainfall and the onset date. Fig. 3b shows the correlation field calculated with rainfall data from the period 1975-1997. Although the percentage of the area with significant correlation is greater than in the end case, the degrees of freedom were estimated as only 5 . The different number of degrees of freedom with respect to the CCA is because, now, the correlation is made with monthly totals instead of pentads. According to the binomial distribution, the percentage of surface with significant correlation only suffices to claim that it is not caused by chance with a $20 \%$ probability of being wrong. Over southern Brazil, there is an opposite correlation sign with respect to the end case. This is consistent with the very similar patterns of the first modes of the intra-seasonal variability in both seasons (Fig. 2a,b). A positive onset date anomaly means a delay in the convection over most of central and northeastern Brazil, and according to the first mode, this would favor increased precipitation in southern Brazil. On the other hand, there is no anti-symmetry with respect to the end date case in Argentina because early (delayed) onsets tend to be associated with greater (lower) than normal rainfalls. This feature is addressed in the next section.

\section{COMPOSITE PATTERNS ASSOCIATED WITH AN EARLY OR DELAYED END AND ONSET OF THE SASM}

\subsection{End of the convective season}

Another way to explore the relation between the inter-annual variability of the monsoon end date and the subtropical rainfall in May is to compose this variable separately for the years in which the monsoon end has occurred early or late. To do this, the years were classified into 3 groups with advanced, normal or delayed end dates. The limit between normal cases and delayed (advanced) was fixed at the average end date plus (less) 6 d, i.e. approximately half the interannual standard deviation of the end date. This makes the number of such cases almost equally probable. Thus, the years 1980, 1981, 1983, 1984, 1987, 1990, 1992 and 1993 were grouped as the early end set. Likewise, the delayed end set comprised the years 1977 , 1979，1986，1989，1991，1994，1995 and 1996. The greatest difference between the composite precipitations of these 2 sets is in southern Brazil, but there are important differences all along the eastern part of subtropical South America (Fig. 4a). To illustrate the rela-
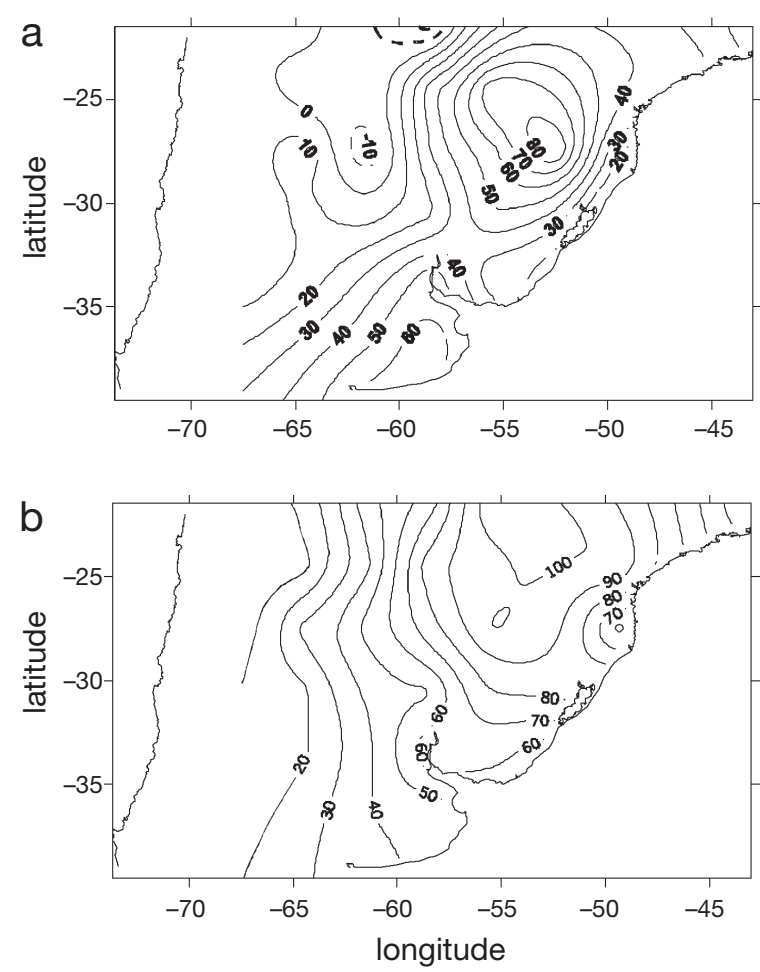

Fig. 4. (a) Composite May rainfall difference (mm) between years with an early end (1980, 1981, 1983, 1984, 1987, 1990, 1992 and 1993) and those with a delayed end (1977, 1979, 1986, 1989, 1991, 1994, 1995 and 1996). (b) Standard deviation of May rainfall (mm) 


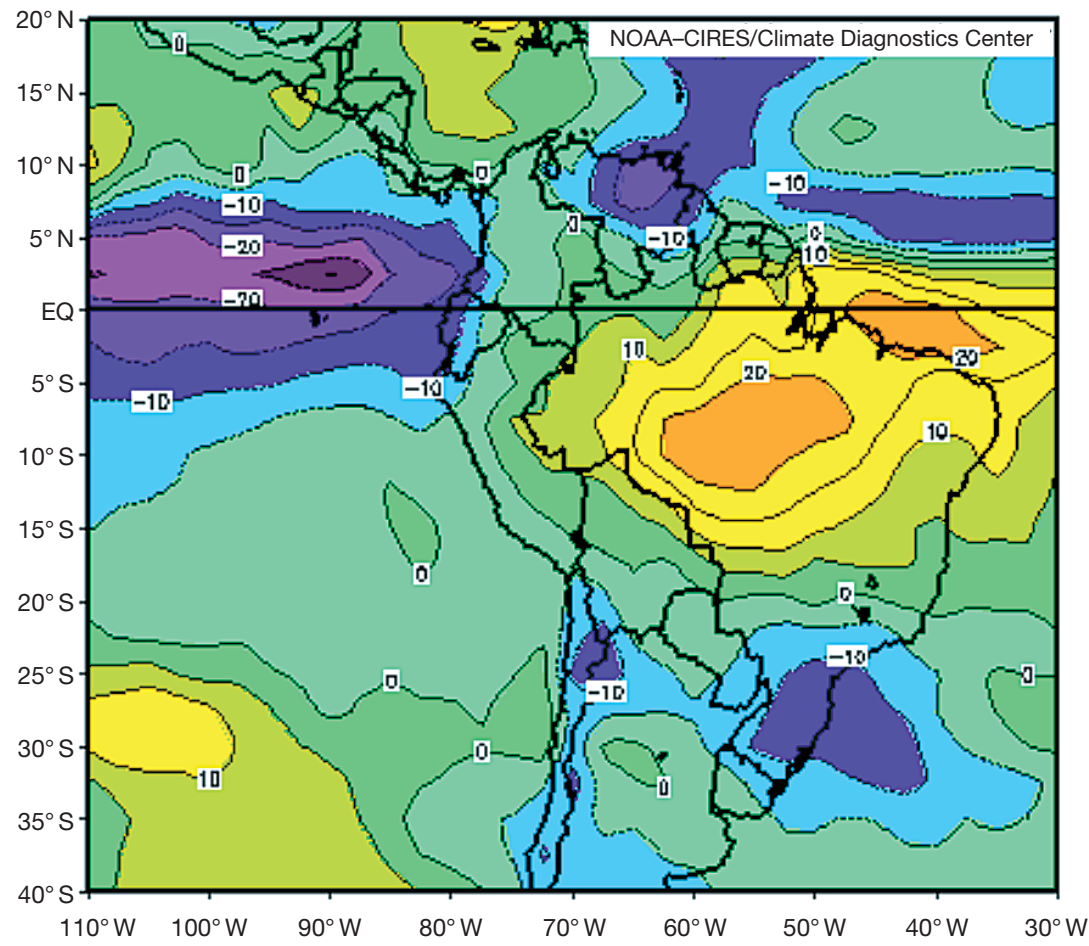

Fig. 5. Composite May OLR difference $\left(\mathrm{W} \mathrm{m}^{-2}\right)$ between years with an early and a delayed end

tive importance of these differences, Fig. $4 \mathrm{~b}$ shows the averaged standard deviation of the inter-annual rainfall for May.

The maximum OLR difference between the early and the delayed end composites in May is over central Brazil, at about $10^{\circ} \mathrm{S}$ (Fig. 5). A center of opposite difference is the eastern sector of subtropical South America, coinciding with the position of the main difference in precipitation (Fig. 4a). More convection is also observed over the equatorial Pacific in years with an early end date. This is consistent with the fact that when the eastern equatorial Pacific is warmer (colder) the upward vertical motion and the rainfall over tropical South America are weaker (stronger) than normal (Kousky 1999). This signal suggests a relation with the El Niño-La Niña phenomenon, although not every El Niño has been accompanied by an early end, or every La Niña by a delayed one, as can be seen from the years listed in the previous paragraph for both cases. South of $30^{\circ} \mathrm{S}$, the correspondence between the OLR and precipitation differences is not as good, because OLR as a proxy for precipitation becomes increasingly less satisfactory with latitude.

Fig. 6 shows the difference between the composite of the omega vertical velocity at $500 \mathrm{hPa}$ for the month of May between years with early monsoon end minus those with delayed end. Over South America, the most important difference is over eastern Argentina, southern Brazil, Uruguay and Paraguay, with more upward vertical motion in years when the monsoon ends earlier than in years when it ends later, which is consistent

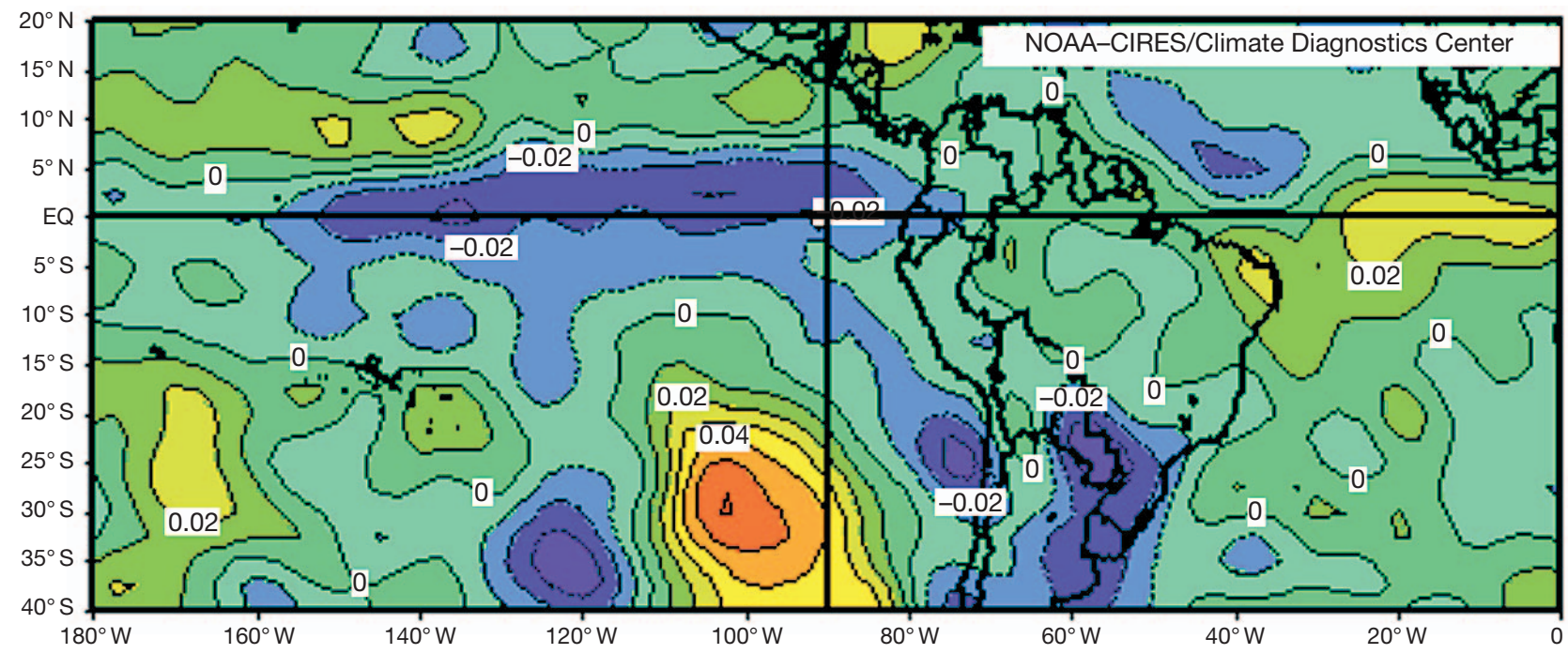

Fig. 6. Composite May $500 \mathrm{hPa}$ omega vertical velocity difference (hPa s${ }^{-1}$ ) between years with an early and a delayed end 
with the respective precipitation differences (Fig. 4a). In the case of the tropical region, the differences in the vertical velocity field are very small, not only at $500 \mathrm{hPa}$, but also at 400 and $300 \mathrm{hPa}$ (not shown). However, convection differences as estimated by OLR are important (Fig. 5), suggesting that these OLR differences are caused by changes in processes that do not alter the monthly average vertical velocity. They could be forced by, for instance, to a change in the diurnal pattern of convection or in the transient modes, some of which could be related to or even forced by the subtropical activity. The latter is suggested by the wavelike structure in the subtropical Pacific (Fig. 6) and, consequently, the link between subtropical rain in May and the monsoon end could be related in part to this common remote forcing. Likewise, the fact that the subtropical rainfall, among other forcings, may contribute to modulate the monsoon end cannot be disregarded.

Another indication that the dynamics of the subtropical atmosphere is related to the end date of the monsoon is that the location of the subtropical jet in May varies according to this date. Considering that the latitude of the maximum westerlies at $200 \mathrm{hPa}$ at this time of the year is $30^{\circ} \mathrm{S}$ (Doyle 1994), the difference between the composites of the $200 \mathrm{hPa}$ wind vector shows a tendency toward a more (less) intense jet shifted to the northwest (southeast) with earlier (later) end of the monsoon (Fig. 7). This is also reflected in the correlation between the end date and the jet intensity

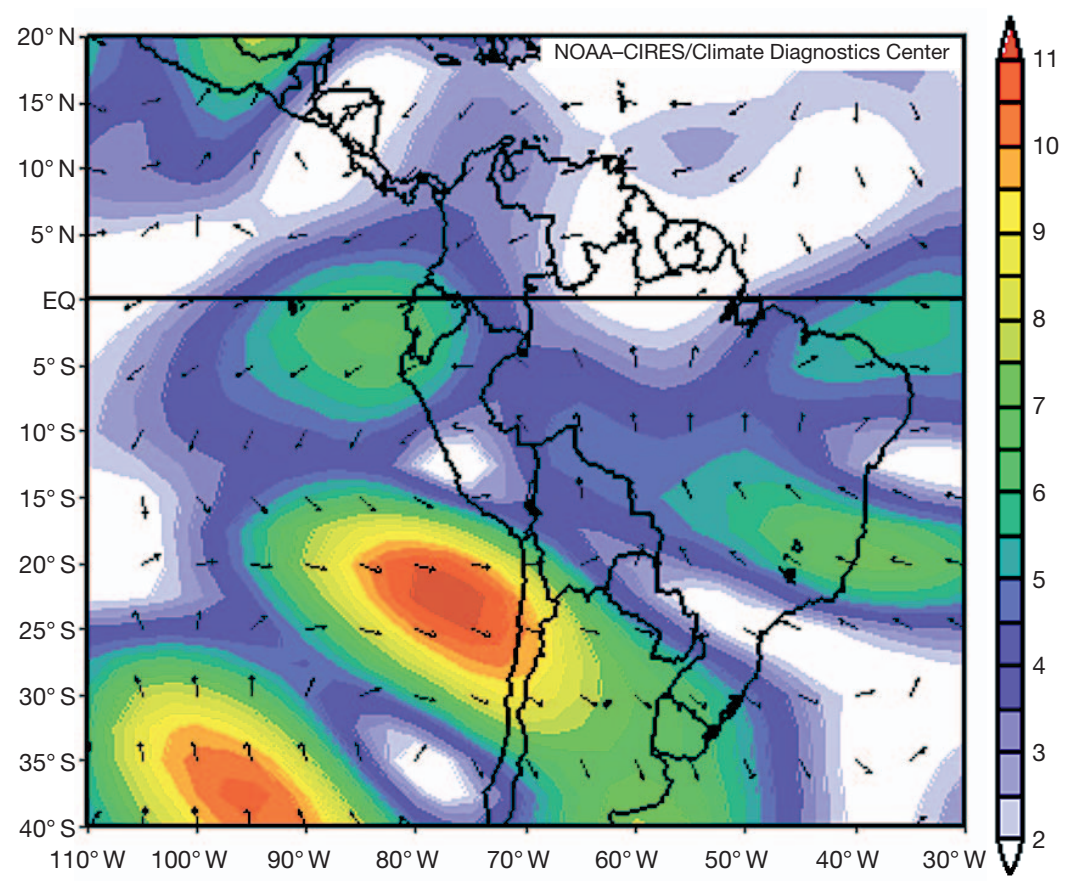

Fig. 7. Composite May $200 \mathrm{hPa}$ zonal wind difference $\left(\mathrm{m} \mathrm{s}^{-1}\right)$ between years with an early and a delayed end. The shaded areas denote wind intensity
$(-0.45)$, which is significant at the $95 \%$ confidence level. These relations could be related to the fact that early (late) ends are related to upward (downward) vertical velocity and increased convective activity in the coastal area of Colombia and over Ecuador (Figs. 6 \& 7), which, in turn, enhances (reduces) the momentum transport to the south through Hadley circulation. This argument is consistent with the fact that the OLR over the area between $10^{\circ} \mathrm{N}-5^{\circ} \mathrm{S}$ and $70-80^{\circ} \mathrm{W}$ has a significant correlation of 0.41 (90\% confidence level) with the $200 \mathrm{hPa}$ maximum wind latitude over the South American Pacific coast. That implies a tendency toward a northern (southern) position of the subtropical jet when the convection is greater (lower) than normal over the coastal area of Colombia and over Ecuador.

The composite low-level moisture flows $(q \cdot V)$ in May for years with early and delayed monsoon end, as well as their difference, are presented in Fig. 8. There is an increased (decreased) advection of moisture from the tropical continental region toward the eastern subtropical region with an earlier (delayed) end of the monsoon. The magnitude of the moisture flow difference toward Southern Brazil, Uruguay and Eastern Argentina is considerable when compared with the values of any of the 2 extreme composites (Fig. 8a,b). This difference results from a more pronounced anticyclonic circulation over the continent that reaches lower latitudes $\left(10^{\circ} \mathrm{S}\right)$ in the early end cases (Fig. 8a,b) than in the delayed ones. Another difference can be observed on the coast of Chile, where the anticyclonic circulation is further west in the delayed case than in the early one. This feature is consistent with the vertical velocity difference between the 2 cases (Fig. 6). But what is more relevant to the purpose of this paper is that the subtropical regions with positive (negative) precipitation differences between early and delayed onset cases have an enhanced (reduced) low-level moisture flow from tropical South America (Fig. 8c), indicating how determinant this flow is in the regional precipitation.

It can be concluded that the interannual variability of the SASM end is associated with important changes in the mean low-level advection of moisture, the mean vertical velocity and precipitation over the eastern part of subtropical South America. Apparently, this association could be related both to the variability in the progress of the Atlantic High over the continent in 

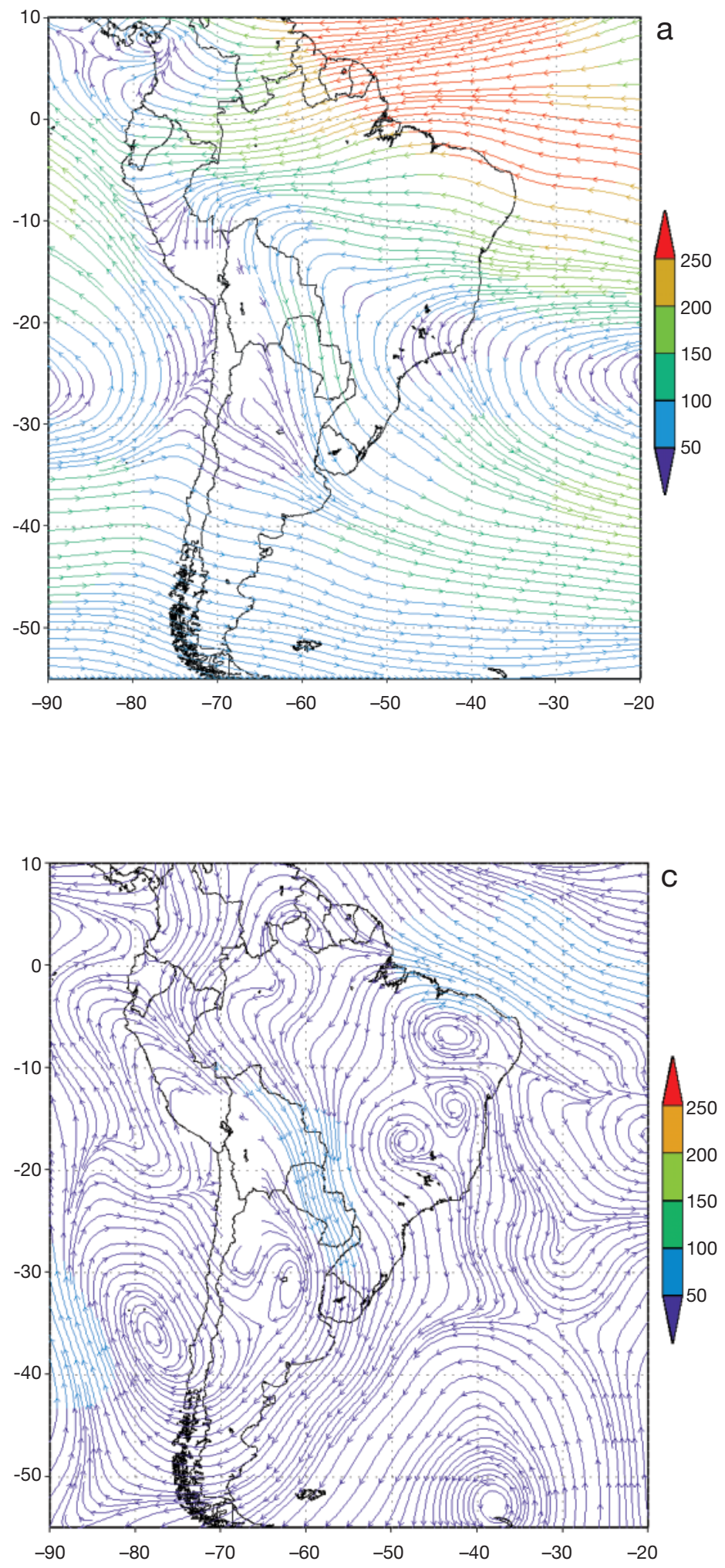

Fig. 8. Composite May moisture flow $(V \cdot q)\left(\mathrm{mm} \mathrm{m} \mathrm{s}^{-1}\right)$ for years (a) with an early end and (b) with a delayed end; (c) the difference between them. Years in each set as in Fig. 4

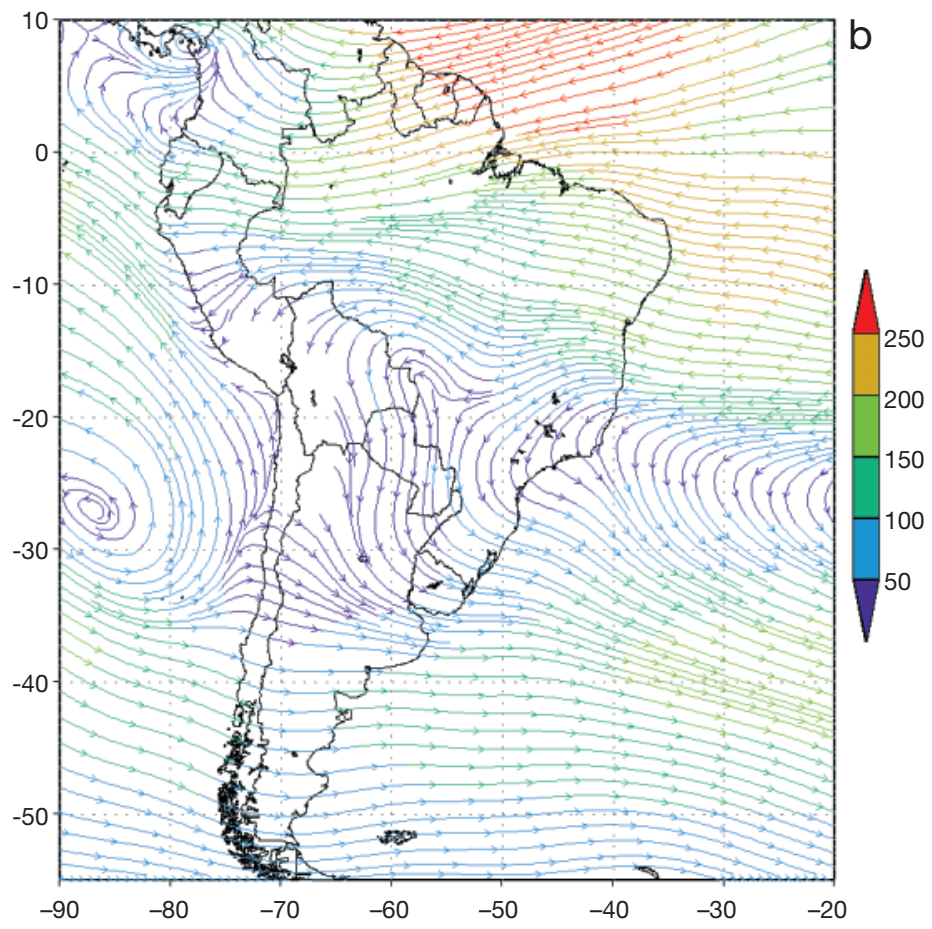

its shift to lower latitudes during the autumn, which conditions the low-level moisture flow, and to midlatitude processes that influence both the subtropical and the tropical South American atmosphere.

\subsection{Onset of the convective season}

The differences between September rainfall composites calculated with years with an early onset of the tropical convection (1979, 1982, 1984, 1986, 1992 and 1996) and with years with a delayed onset $(1975,1976$, 1981, 1987, 1989, 1994, 1995 and 1997) are shown in Fig. 9a. The years with an early and a delayed onset were chosen using a criterion similar to the one employed in the case of the monsoon end. There are positive differences over subtropical Argentina and Uruguay that are considerably larger than the interannual standard deviation at their nucleus region, located at about $30^{\circ} \mathrm{S}$ (Fig. 9a,b). Following a pattern similar to that in the correlation field (Fig. 3b), there are negative differences in southern Brazil, indicating that this region, closer to the tropical convection activity, tends to have inhibited precipitation with earlier tropical convection. This is consistent with the first intra-seasonal mode pattern, considering that earlier onsets mean enhanced convection in central and northeastern Brazil. Regarding the positive difference 

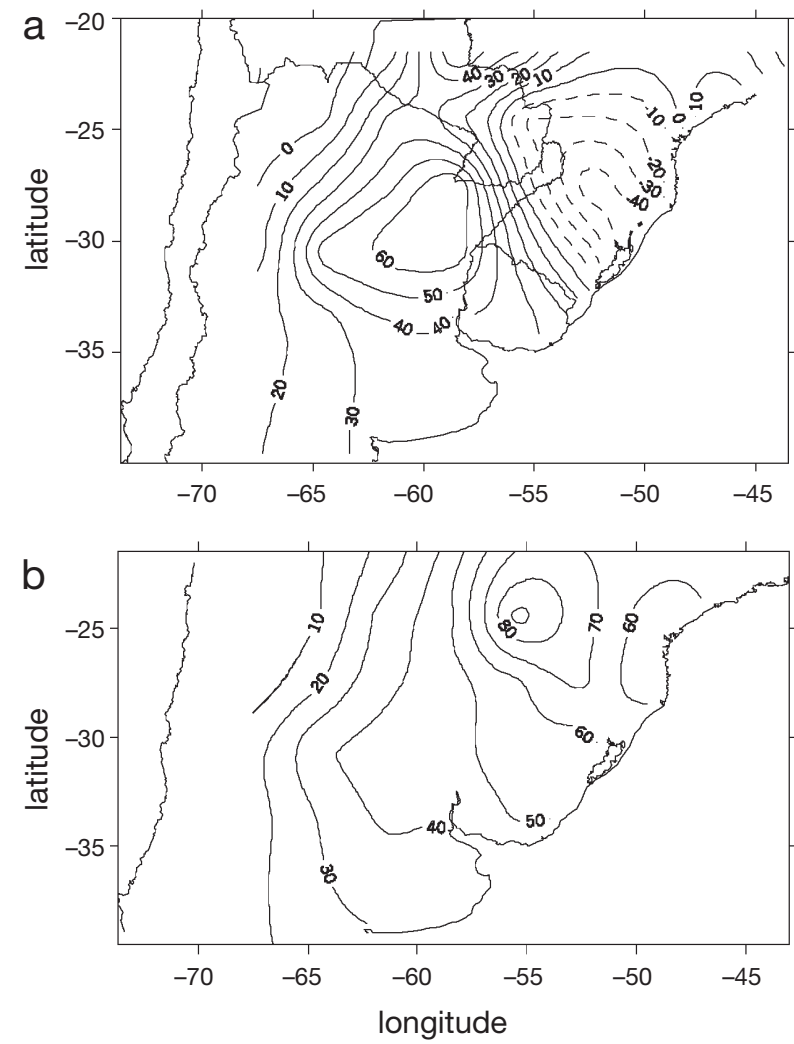

Fig. 9 (a) Composite September rainfall difference (mm) between years with an early onset (1979, 1982, 1984, 1986, 1992 and 1996) and those with a delayed onset $(1975,1976,1981$, 1987, 1989, 1994, 1995 and 1997). (b) Standard deviation of May rainfall (mm) small positive differences in OLR. This could be due to the fact that OLR sometimes represents cirrus clouds, which can be present even without rainfall, or to the fact that rainfall is highly dependent on transient modes that are not reflected in the monthly OLR means. The possibilities of this mismatch are higher when the differences in the mean OLR field are small.

The main feature of the composite difference field of the September $500 \mathrm{hPa}$ omega vertical velocities is a large center over central Brazil and a band stretching from southern Brazil to Paraguay (Fig. 11). Although there are some differences concerning the respective OLR field, there is a qualitative agreement with regard to this pattern. The area of the southern center seems to be larger and more extended to the west than the respective centers observed in the OLR and in the precipitation fields (Figs. 9 \& 10), indicating that another factor in addition to the mean vertical motion, probably the transient activity, is determinant of the rainfall over Paraguay during this month. Contrary to what occurs in the autumn case, the difference pattern shows compensatory vertical motions between the tropical and subtropical region.

Since in September the latitude of the maximum westerlies over South America is around $30^{\circ} \mathrm{S}$, in the cases with an early (delayed) onset date the subtropical jet tends to be less (more) intense (Fig. 12). Also, the correlation between the onset date and the intensity of the jet (0.46) is significant at the $95 \%$ confidence level. over subtropical Argentina and Uruguay, it can be partially related to the first mode of the intra-seasonal variability of the spring rainfall, as this mode has an opposite variability in Southern Brazil and in the Buenos Aires Province (Fig 3b). This latter feature is not present in the autumn first mode, being one of the small dissimilarities between the spring and the autumn first modes (Fig. 3a,b).

The maximum difference between OLR composites in September is over central Brazil, indicating that enhanced convection tends to occur in years when an early onset of the monsoon takes place. In addition, less convection than normal is observed in the Pacific Ocean and over Southern Brazil (Fig. 10). The latter is consistent with the rainfall difference (Fig. 9a). As in May, south of $30^{\circ} \mathrm{S}$ the correspondence between the OLR and precipitation differences is poor. An inconsistency with rainfall differences appears over Paraguay, where there are

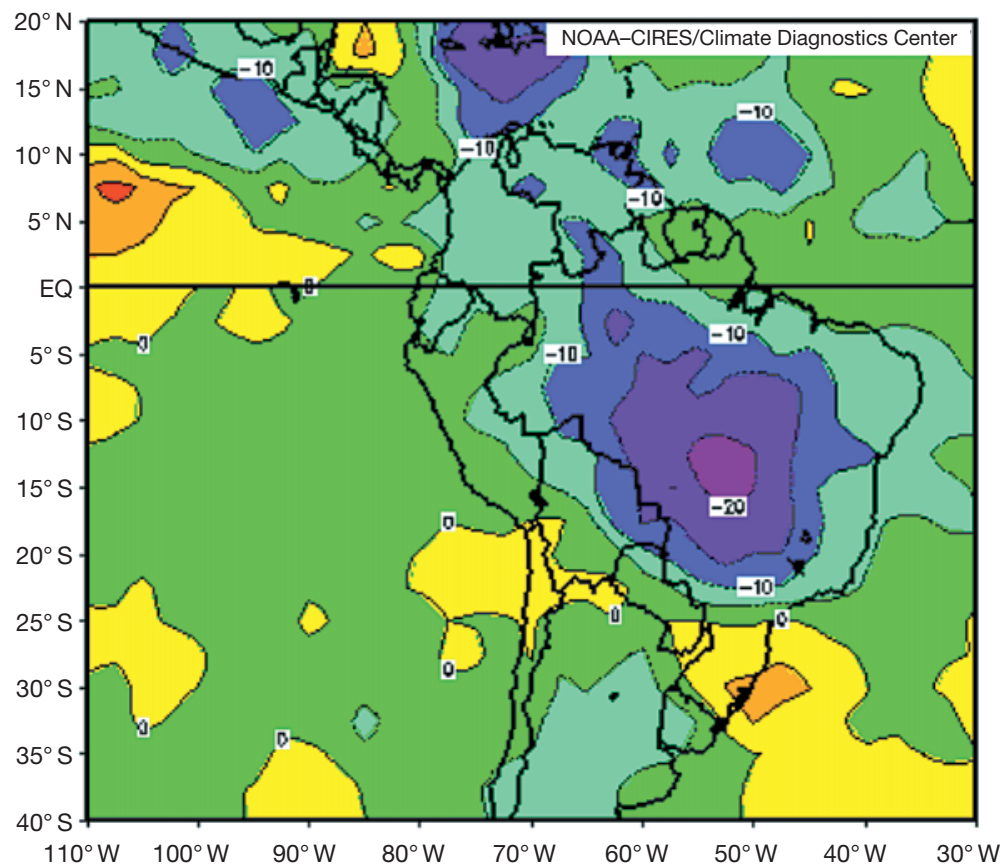

Fig. 10. Composite September OLR difference $\left(\mathrm{W} \mathrm{m}^{-2}\right)$ between years with an early and a delayed onset 


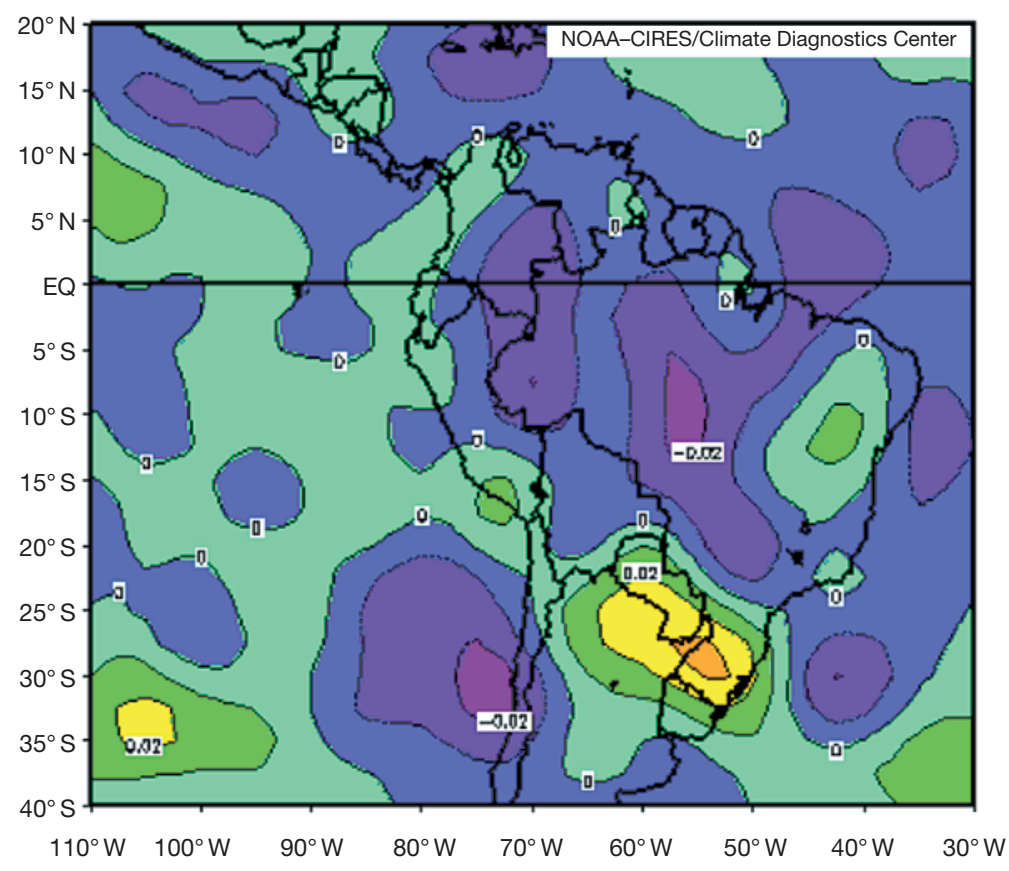

Fig. 11. Composite September $500 \mathrm{hPa}$ omega vertical velocity difference $\left(\mathrm{hPa} \mathrm{s}^{-1}\right)$ between years with an early and a delayed onset

(Fig. 13a,b). Again, as in May, and with the exception of Eastern Paraguay, subtropical regions with positive (negative) precipitation differences between early and delayed onset cases have enhanced (reduced) low-level moisture flow from tropical South America (Fig. 13c). This result reinforces the concept that this low-level moisture flow is determinant for precipitation in this region.

As in the case of the SASM end, it can be concluded that the inter-annual variability of the SASM onset is associated with changes in the mean low-level advection of moisture, the mean vertical velocity and precipitation over subtropical Argentina and the eastern part of subtropical South America. Contrary to the end case, the differences between early and delayed onset cases present mean vertical velocity differences between southern Brazil and Paraguay and central Brazil that are opposite in sign. Therefore, mechanisms of compensatory subsidence between those regions cannot be ruled out. Furthermore, in most of subtropical Argentina, Uruguay and southern Brazil, enhanced (reduced) low-level moisture flow from tropical South America are

The September composite low-level moisture flows for years with early monsoon end and those with delayed end, as well as their difference, are presented in Fig. 13. There is a considerably decreased (increased) advection of moisture from the tropics toward Eastern Paraguay and southern Brazil associated with earlier (delayed) monsoon onset. However, since at the same time there is also a change in the direction of the moisture flow, there is an increment (reduction) of the moist advection from the tropics with an earlier (delayed) onset date of the monsoon over most of Argentina and Uruguay (Fig. 13c). Also, the difference field shows that early onsets have an enhanced convergence with respect to the delayed onsets in the northwest of South America, which is consistent with the fact that this is the region where the onset of the convective season first begins (Fig. 13c). As in the case of May, the magnitude of the difference in the moisture flow toward southern Brazil, Uruguay and subtropical Argentina is considerable when compared with the values of any of the 2 extreme composites

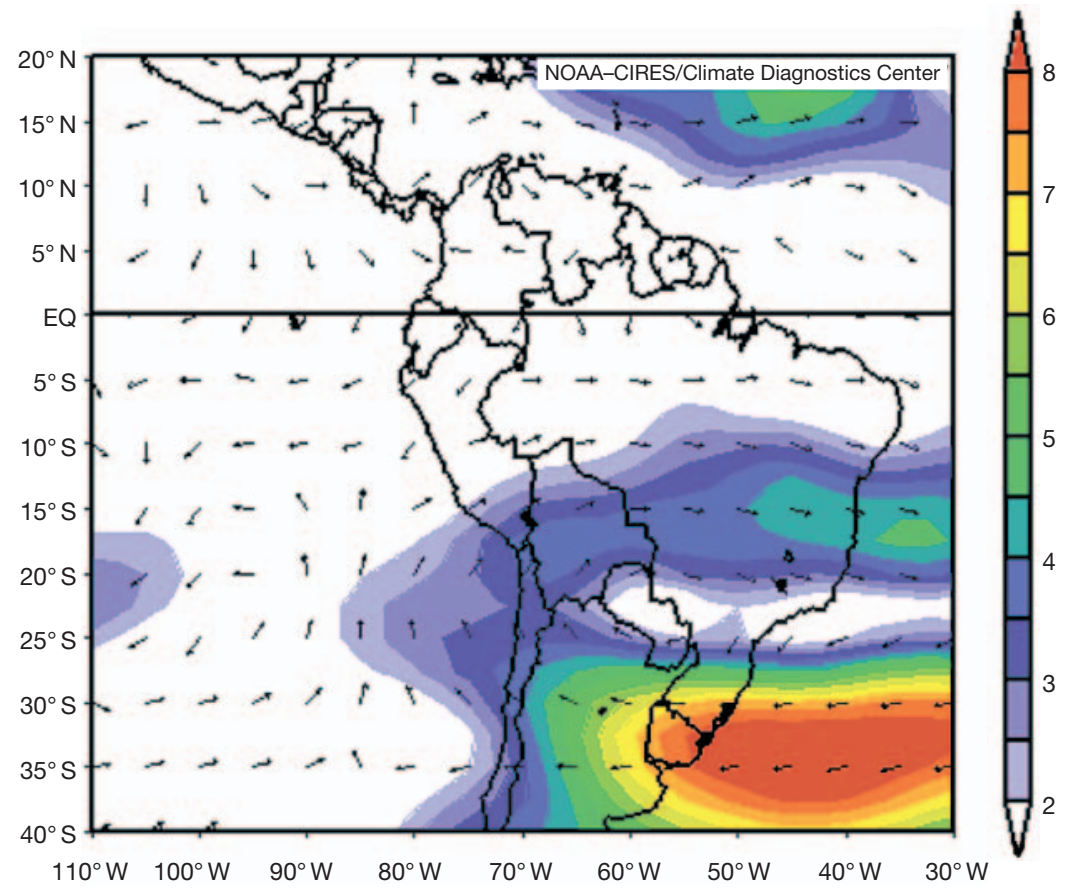

Fig. 12. Composite September $200 \mathrm{hPa}$ zonal wind difference $\left(\mathrm{m} \mathrm{s}^{-1}\right)$ between years with an early and a delayed onset. The shaded areas denote wind intensity 

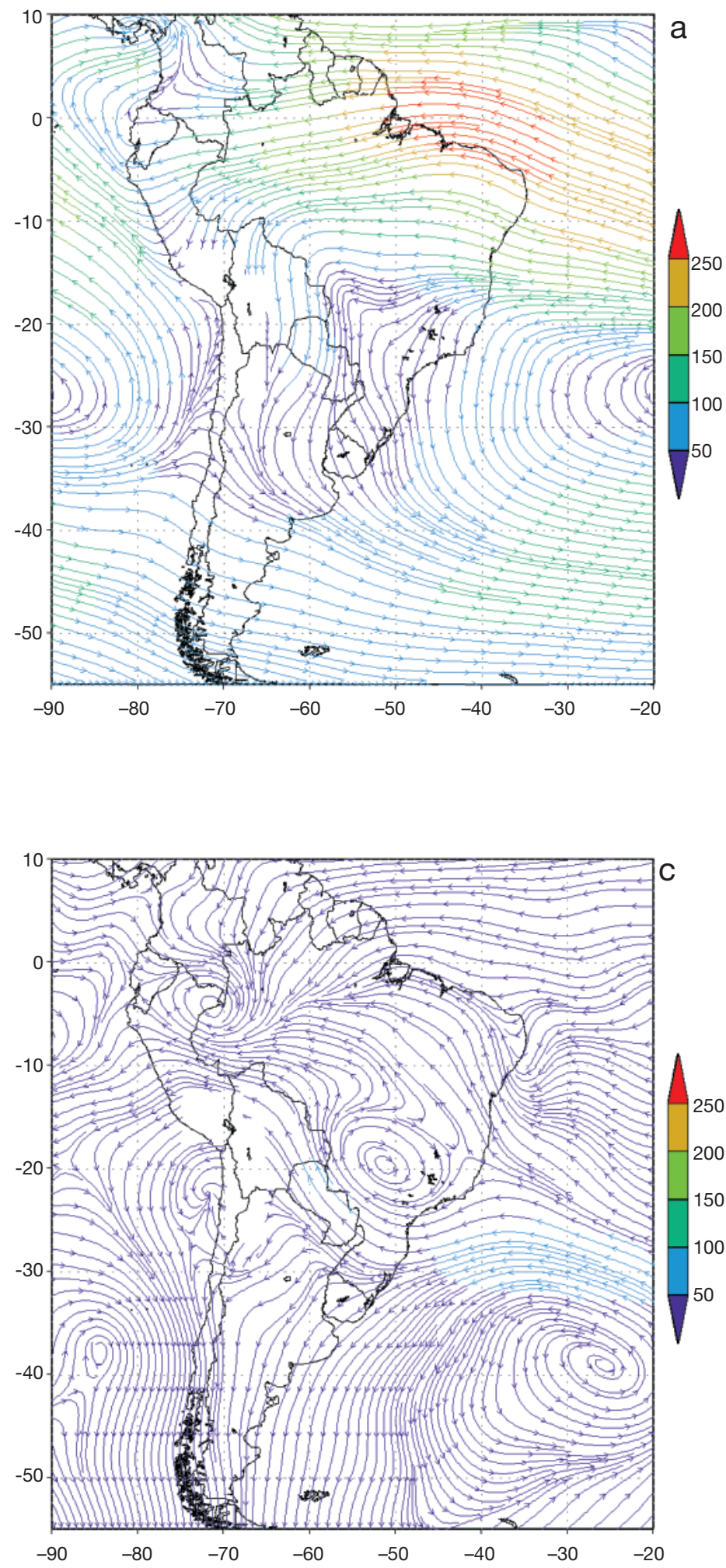

Fig. 13. Composite September moisture flow $(V \cdot q)(\mathrm{mm} \mathrm{m}$ $\mathrm{s}^{-1}$ ) for years (a) with an early onset and (b) with a delayed onset; (c) the difference between them. Years in each set as in Fig. 4

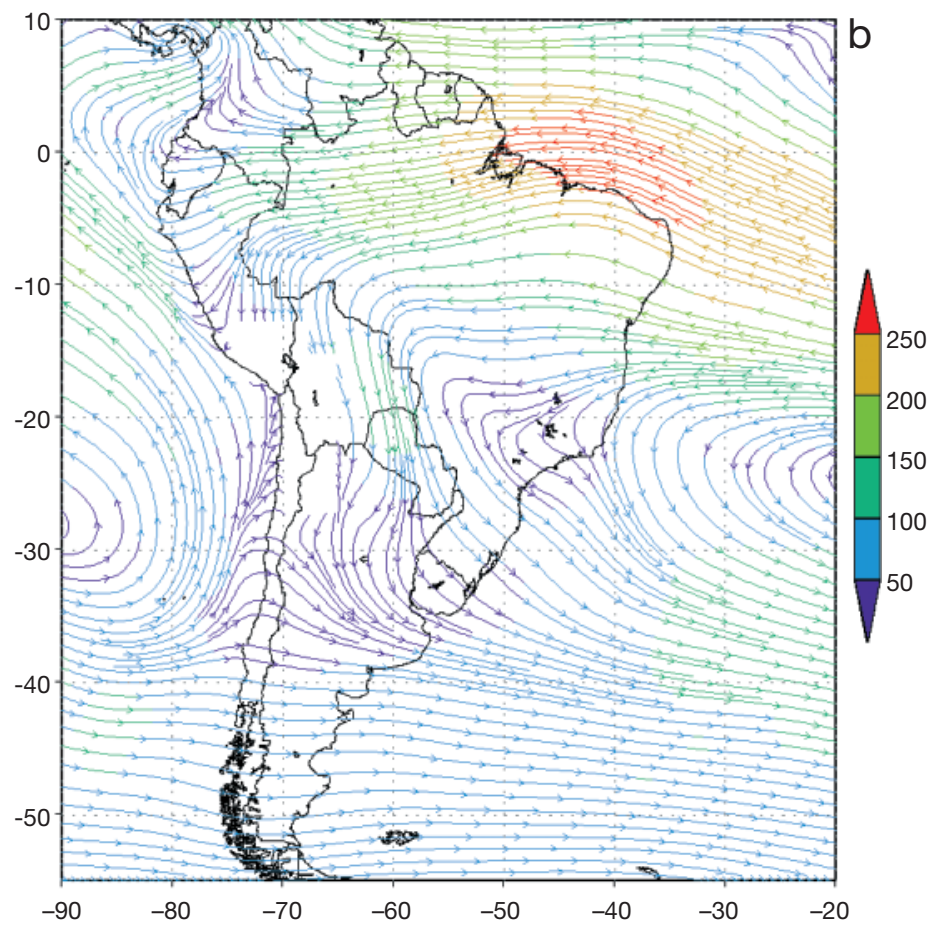

\section{SUMMARY AND CONCLUDING REMARKS}

Convection over tropical South America is related to subtropical rainfall during the transition seasons. The first modes of the CCA in autumn and spring are very similar. They have an opposite pattern between tropical convection and subtropical rainfall in the east of the continent. The austral center in southern Brazil is approximately at the position of the maximum in the seasonal rainfall. Because a delay (an early advent) of the monsoon end increases (reduces) the period with convection over the tropics and the contrary occurs with the onset, these dates could be expected to correlate with rainfall in southern Brazil during May and September, as indeed occurs. In addition, during May the end date is negatively correlated with rainfall in most of the subtropical region, except in northwestern Argentina. However, in September, the onset is positively correlated with rainfall only in southern Brazil, while in Argentina and Uruguay the correlation is highly negative, not showing a symmetry with respect to the May case. The differences in precipitation patterns between years with early and delayed monsoon end or onset dates are spatially consistent with the respective correlation patterns.

In May, the mean low-level flow of moisture is substantially greater over eastern subtropical South America in the cases with advanced monsoon end than in those with a delay end. Consistent with the rainfall 
difference, the convection in this region-as estimated by OLR - and the rising vertical motion are also greater in the early end case than in the delayed one. In central Brazil, the OLR difference has an opposite sign with respect to that in eastern subtropical South America. However, the composite differences of the vertical velocity in the middle and upper troposphere do not show considerable alterations. This is probably so because the tropical convection differences, detected by the OLR composite, are related to processes such as transient modes, which do not alter the mean monthly vertical velocity.

In September, the composite differences between years with early and delayed onsets show an enhanced moisture advection from the tropical continent over most of Argentina and Uruguay, and a reduction over southern Brazil and Paraguay. During this month, the vertical velocity composite differences show a dipole pattern relationship between the tropics and the subtropical regions, but its correspondence with the composite difference rainfall and OLR subtropical fields is good only in southern Brazil. Regarding the important difference in precipitation composites over subtropical Argentina and Uruguay, which does not have a similar counterpart in May, it is accompanied by the different moisture advection from the tropical continent. With respect to this aspect, all the composite differences indicate that the low-level moisture flow from the tropical continent is determinant for May and September precipitation over eastern subtropical South America.

Acknowledgements. This work was supported by the PIP4493 CONICET grant and BID-802/OC-AR-PICT 04465 grant. The authors are grateful to NOAA-CIRES Climate Diagnostics Center, Boulder, Colorado, USA, for the permission to include OLR, $200 \mathrm{hPa}$ wind and $500 \mathrm{hPa}$ omega velocity images for Figs. 5, 6, 7, 10, 11 \& 12 taken from the Website http://www.cdc.noaa.gov/.

\section{LITERATURE CITED}

Aceituno P (1988) On the functioning of the Southern Oscillation in the South American sector. Part I: surface climate. Mon Weather Rev 116:505-524

Aceituno P, Garreaud R (1995) Impacto de los fenómenos El Niño y La Niña en regímenes fluviométricos andinos. Rev Soc Chilena Energía Hidraúlica 10:33-43

Arkin PA, Ardanuy PE (1989) Estimating climatic scale precipitation from space: a review. J Clim 2:1229-1238

Diaz AF, Studzinski CD, Mechoso CR (1998) Relationship between precipitation anomalies in Uruguay and Southern Brazil and sea surface temperature in the Pacific and Atlantic Oceans. J Clim 11:251-271

Douglas M, Nicolini M, Saulo C (1998) Observational evidences of a low level jet east of the Andes during January-March 1998. Meteorologica 23:63-72

Doyle M (1994) Maximum 200 and $300 \mathrm{hPa}$ winds in the South-American sector and near ocean. Seminar, Depart- ment of Atmospheric Science, University of Buenos Aires Doyle M (2001) On some of the factors controlling summer precipitation in subtropical Argentina. $\mathrm{PhD}$ thesis, University of Buenos Aires

Doyle M, Barros V (2000) Relationship between water vapor sources and rainfall over Southern South America. In: Sixth International Conference on Southern Hemisphere Meteorology and Oceanography. American Meteorological Society, Santiago de Chile, p 260-261

Fu R, Zhu B, Dickinson R (1999) How does the atmosphere and land surface influence the seasonal changes in convection in Tropical Amazon? J Clim 12:1306-1321

Gandú AW, Silva Diaz PL (1998) Impact of tropical heat sources on the South American tropospheric circulation and subsidence. J Geophys Res 103:6001-6015

González M, Barros V (1996) Statistical features of mean rainfall annual cycle and its anomalies in subtropical Argentina. Meteorologica 21:15-26

González M, Barros V (1998) The relation between tropical convection in South America and the end of the dry period in subtropical Argentina. Int J Climatol 18:1669-1685

González M, Barros V (2000) South American monsoon onset and end date prediction using outgoing longwave radiation and sea surface temperature. In: Sixth International Conference on Southern Hemisphere Meteorology and Oceanography. American Meteorological Society, Santiago de Chile, p 124-125

Green P (1978) Analyzing multivariate data, Chapters 8 and 9. Dryden Press, Hinsdale, IL

Grimm A, Ferraz S, Gomez J (1998) Precipitation anomalies in Southern Brazil associated with El Niño and La Niña events. J Clim 11:2863-2880

Grimm A, Barros V, Doyle M (2000) Climate variability in Southern South America associated with El Niño and La Niña events. J Clim 1:35-58

Gruber A, Krueger AF (1984) The status of the NOAA outgoing longwave radiation data set. Bull Am Meteorol Soc 65:958-962

Hastenrath S (1984) Interannual variability and annual cycle: mechanisms of circulation and climates in the tropical America sector. Mon Weather Rev 112:1097-1107

Heddinghaus T, Krueger A (1981) Annual and interannual variations in outgoing longwave radiation over the tropics. Mon Weather Rev 109:1208-1218

Horel JD, Hahmann AN, Geisler JE (1989) An investigation of the annual cycle of convective activity over the tropical Americas. J Clim 2:1388-1403

Janowiak JE, Krueger AF, Arkin PA, Gruber A (1985) Atlas of outgoing lonwave radiation derived from NOAA satellite data. NOAA Atlas no. 6, NOAA/NWS/NESDIS, US Departament of Commerce, Silver Spring, MD

Kalnay E, Kanamitsi M, Kistler R, Collins W and 18 others (1996) The NCEP/NCAR reanalysis 40 years-project. Bull Am Meteorol Soc 77:437-471

Kiladis G, Diaz H (1989) Global climatic anomalies associated with extremes in the Southern Oscillation. J Clim 2: 1069-1090

Kousky VE (1988) Pentad outgoing longwave radiation climatology for the South America sector. Rev Brasilera Meteorol 3:217-231

Kousky VE (1999) The South American monsoon system. In: 10th Global Change Studies. American Meteorological Society, Dallas, p 215-217

Labraga J, Frumento O, Lopez M (2000) The atmospheric water vapor cycle in South America and the tropospheric circulation. J Clim 13:1899-1915

Lenters J, Cook K (1995) Simulation and diagnosis of the 
regional summertime precipitation climatology of South America. J Clim 8:2988-3005

Liebmann B, Hartmann D (1982) Interannual variations of outgoing IR associated with tropical circulation changes during 1974-78. J Atmos Sci 39:1153-1162

Livezey R, Chen W (1983) Statistical field significance and its determination by Monte Carlo techniques. Mon Weather Rev 111:46-59

Marengo J, Liebmann B, Kousky V, Filizola N, Wainer I (2001) Onset and end of the rainy season in the Brazilian Amazon basin. J Clim 14:833-852

Mitchell T, Wallace J (1992) The annual cycle in equatorial convection and sea surface temperature. J Clim 5:1140-1156

Mo KC, Higgins RW (1996) Large-scale atmospheric moisture transport as evaluated in the NCEP/NCAR and NASA /DAO reanalysis. J Clim 9:1531-1545

Morrissey ML, Graham NE (1996) Recent trends in rain gauges precipitation measurements from the tropical Pacific: evidence for an enhanced hydrological cycle. Bull Am Meteorol Soc 77:1207-1219

Nogués-Paegle J, Mo KC (1997) Alternating wet and dry conditions over South America during summer. Mon Weather Rev 125:279-291

Paegle J (2000) American low level jets in observation and theory: the All project. In: Sixth International Conference on Southern Hemisphere Meteorology and Oceanography. American Meteorological Society, Santiago de Chile, p 161-162

Prohaska FJ (1976) Climates of Central and South America. In: Schwerdtfeger W (ed) World survey of climatology. Elsevier, Amsterdam, p 57-69

Editorial responsibility: Hans von Storch, Geesthacht, Germany
Randel DL, Vonder Haar TH, Ringerud MA, Stephens GL, Greenwald TJ, Combs CL (1996) A new global water vapor dataset. Bull Am Meteorol Soc 77:1233-1246

Rao V, Hada K (1990) Characteristics of rainfall over Brazil: annual variations and connections with the Southern Oscillation. Theor Appl Climatol 42:81-90

Ropelewski CF, Halpert MS (1996) Quantifying Southern Oscillation precipitation relationships. J Clim 9: 1043-1059

Schmetz J, Liu Q (1988) Outgoing longwave radiation and its diurnal variation at regional scales derived from Meteosat. J Geophys Res 11:192-203

Silva Diaz PL (2000) The role of latent heat release in the dynamics of the LLJ's along the Andes. In: Sixth International Conference on Southern Hemisphere Meteorology and Oceanography. American Meteorological Society, Santiago de Chile, p 163-165

Sugahara S (1991) Fluctuacões interanuais, sazonais e intrasazonais da precipitação no estado de Sao Paulo. Tese de Doutorado, Departamento de Ciencias Atmosféricas, Universidade de Sao Paulo

Wang M, Paegle J (1996) Impact of analysis uncertainty upon regional atmospheric moisture flux. J Geophys Res 101: 7291-7303

Zhou J, Lau KM (1997) Climatology of the South American monsoon. In: 5th International Conference on Southern Hemisphere Meteorology and Oceanography, Pretoria, South Africa. American Meteorological society, Pretoria, p 160-161

Zhou J, Lau KM (1998) Does a monsoon climate exist over South America? J Clim 11:1020-1040

Submitted: September 1, 2000; Accepted: March 26, 2002 Proofs received from author(s): June 3, 2002 